\title{
THE EXPERIMENTAL POSITIONS OF IDEAS IN KNOWLEDGE SYNTHESIS
}

\author{
A.J. Roycroft \\ London, England
}

Although I have (quite properly) never had access to the actual TI computer records of the 20 KBBKN experimental positions I was tested against, I do have my handwritten records. I have just checked the 20 starting positions as I have them and as they are published as table 1 (p. 6) in Michie and Bratko's article, "Ideas on Knowledge Synthesis Stemming from the KBBKN Endgame" (ICCA Journal, Vol. 10, No. 1, pp. 3-13). There are two discrepancies :

- No. 3 is totally different, namely WKc2, WBb1, WBc7, BKe8, BNg5;

- In No. 6 the Knight is initially on $\mathrm{g} 3$ (not a3).

The last discrepancy, in a footnote in the original article announced as a clerical error, is now satisfactorily solved.

With respect to No. 3, I may inform you that among my sheets there is a record of the printed position of No. 3 but the play stops after 10 moves, presumably because of a program bug - we had about three at various times.

\section{GIVEN A QUEEN, WHAT PRICE THE ISSUE?}

\section{The Editors}

Hans Zellner has been justifiably annoyed by the erronenous publication (Zellner, 1986) of his total-board numbers from the KQK endgame. The errors were noticed by Mr. Zellner himself as well as by Mrs. Hadek and Mondl (from Vienna), Mr. Van Dijken (from Enschede), Mr. Schlösser (from Bruhl) and Mr. T. Pronk (from Noordwijkerhout). We hasten to correct the table in question.

\begin{tabular}{|lr|}
\hline \multicolumn{2}{|l|}{ KQK } \\
Legal positions: 144,508 (WTM) \\
containing:
\end{tabular}

Needless to say, the results invalidate and replace the left-hand part of the table on p. 200 of Vol. 9, No. 4. The sequence of events, resulting in an erroneous publication even though the true facts were at hand with several authors (e.g., at Delft University of Technology, H.J.J. Nefkens' KQK database) inspired Mr. Zellner to recall E.W. Dijkstra's famous adage: "Testing can show the presence of bugs, but never prove their absence". The Editors concur while apologizing to their readers.

\section{Reference}

Zellner, H. (1986). Compressing Databases down to Micro Size. ICCA Journal, Vol. 9, No. 4, pp. 199200. 